\title{
Use of human urine as a fertilizer for corn, potato, and soybean: A case-study analysis using a reactive model
}

\author{
$\underline{\text { F. Maggi }}{ }^{a}$ and E. Daly ${ }^{b}$ \\ ${ }^{a}$ University of Sydney, School of Civil Engineering, 2006 Sydney, NSW, Australia \\ ${ }^{b}$ Monash University, Department of Civil Engineering, Monash University, Clayton VIC 3800, Australia \\ Email: federico.maggi@sydney.edu.au
}

\begin{abstract}
With the population increasing worldwide and the fast expansion of urban areas, there is an escalating exploitation of natural resources and a large, localized production of waste. The production and provision of food is increasingly consuming land and water, requiring a large use of fertilizers. At the same time, most of the existing waste-water treatment plants in cities are not energetically efficient and are not designed to retrieve and re-use a large proportion of nutrients contained in waste-water. There is thus a compelling need to find alternative uses of waste products to transform them in possible resources. Human liquid waste, available in large quantities in urban areas, might be a good candidate to replace mineral fertilizers.
\end{abstract}

Human urine contains considerable amounts of primary crop nutrients, i.e., nitrogen $(\mathrm{N})$, phosphorous (P) and potassium $(\mathrm{K})$, and secondary nutrients, including sulphur $(\mathrm{S})$, calcium $(\mathrm{Ca})$ and Magnesium $(\mathrm{Mg})$. Trials of human urine applications as an organic fertilizer in small-scale agricultural plots have shown the potential to match the crop yield quantity and quality commonly achieved with mineral fertilizers.

Despite these preliminary studies, knowledge about the performance of urine as an effective fertilizer is still limited. Human urine is a mixture of more than 200 compounds including electrolytes, vitamins, hormones, and other organic and inorganic compounds. About 70 compounds have concentration higher than $10 \mathrm{mg} / \mathrm{L}$, and correspond to a mass of about $36.8 \mathrm{~g} / \mathrm{L}, 8.12 \mathrm{~g} / \mathrm{L}$ of which is $\mathrm{N}$. To date, there is no understanding of the chemical and biological breakdown processes that release end products easily accessible to roots, such as $\mathrm{NH}_{4}^{+}, \mathrm{PO}_{4}^{-3}, \mathrm{~K}^{+}, \mathrm{SO}_{4}^{-2}, \mathrm{Ca}^{+2}$ and $\mathrm{Mg}^{+2}$ ions. Likewise, mechanistic models to help plan fertilization applications to achieve targeted crop yields are not available.

This work thus uses a reaction network of the decomposition pathways of human urine in soils to estimate the release rate of ionic end-products required by plants. The model permits the assessment of the rate of urine applications required to meet the $\mathrm{N}, \mathrm{P}, \mathrm{K}, \mathrm{S}, \mathrm{Ca}$ and $\mathrm{Mg}$ uptake demand in extensive agriculture. We present here the chain of reactions implemented in the model and preliminary results for application in extensive cultivation of corn, potato, and soybean, which are among the most cultivated crops worldwide. The presentation focuses on primary and secondary nutrient uptake supplied by amendments of human urine in various scenarios lasting for 120 days, corresponding to a typical growing season; we considered 3 impulsive applications of human urine at 0,35 , and 80 days at fertilization rates of $0.01,0.05$, and $0.1 \mathrm{~L} \mathrm{~m}^{-2}$ with a dilution ratio of 0.1 ( 1 part of human urine and 9 parts of water).

Results showed that soybean was the only crop to receive the required nutrient amounts with urine applications; conversely, corn and potato plants received less than $70 \%$ of the required primary and secondary nutrients even for the largest fertilization rates tested here.

Although results are preliminary, they suggest that human urine can be effectively used in extensive agriculture to reduce the production and use of synthetic mineral fertilizer. It is possible to envision that a reactive model such as the one presented here may be used to optimized the timing and rate of urine applications. Thus, it is presumable that the effectiveness of urine fertilization may increase beyond the values reported here. Future work should focus on optimization scheme for specific crops and environmental conditions. In addition, the reactive model should be included in a numerical framework to account for transport of aquesous and gaseous species along a soil column.

Keywords: Human Urine, Organic Fertilizer, Nutrients, Crops 


\section{INTRODUCTION}

The reuse of human urine as an alternative fertilizer is receiving increasing attention. Urine contains most of the nutrients of human excreta, and it can yield considerable amounts of nitrogen $(\mathrm{N})$, phosphorous $(\mathrm{P})$, potassium $(\mathrm{K})$, sulphur $(\mathrm{S})$, calcium $(\mathrm{Ca})$, and magnesium $(\mathrm{Mg})$. Knowledge of the performance of human urine to flank, if not replace, mineral fertilization in agriculture is still limited although some studies showed successful use with some crops.

For example, urine applications resulted in similar plant growth characteristics as compared to those using mineral fertilizers (Pradhan et al., 2007) or led to enhanced plant height and leaf length in maize (Guzha et al., 2005). Likewise, tests on tomatoes (Admasson, 2000), red beet (Pradhan et al., 2010a), pumpkin (Pradhan et al., 2010b), maize (Mnkeni et al., 2008) and okra crops (Akpan-Idiok et al., 2012) showed very similar results, all reporting an increased plant biomass as compared to no fertilization, and a yield comparable to or higher than that from mineral fertilizers.

These studies support the idea that human urine is a feasible alternative to mineral fertilizers. Maggi and Daly (2013) have quantified that $90 \%$ of the incoming $\mathrm{N}$ was converted to $\mathrm{NH}_{3}$ and $\mathrm{NH}_{4}{ }^{+}$in a time ranging from 5 to 20 days for instantaneous applications, but conversion could occur more rapidly or slowly depending on the microbial biomass concentration. For other nutrients, there is no current assessment of the rate of conversion to assimilable forms. In addition, an assessment of the extent to which nutrient release from urine amendments meets plant root uptake is also missing.

This work aims at (i) proposing a reaction network of the decomposition pathways in soils of the main compounds detected in human urine, with a particular emphasis to those leading to primary $(\mathrm{N}, \mathrm{P}$, and $\mathrm{K})$ and secondary $(\mathrm{S}, \mathrm{Ca}$, and $\mathrm{Mg})$ nutrients, (ii) estimating the release rate of these nutrient, and (iii) determining to what extent and at which rates human urine can be used to meet the nutrient demand by corn, potato and soybean crops in extensive agriculture.

The proposed reaction network accounts for dissolved compounds that collect up to $90 \%$ of the dry mass in human urine. The model developed on the basis of this reaction network includes mechanisms sufficient to capture the main urine cycle dynamics and fills in the current lack of mechanistic accounting of the release rate and timing of various ions following urine application to soils, and their uptake rate by plants. The model was used to analyze (i) the fraction of nutrient becoming available to selected crops after application of human urin at various rates, and (ii) the dynamics of nutrients over time with respect to time-dependent crop nutrient uptake.

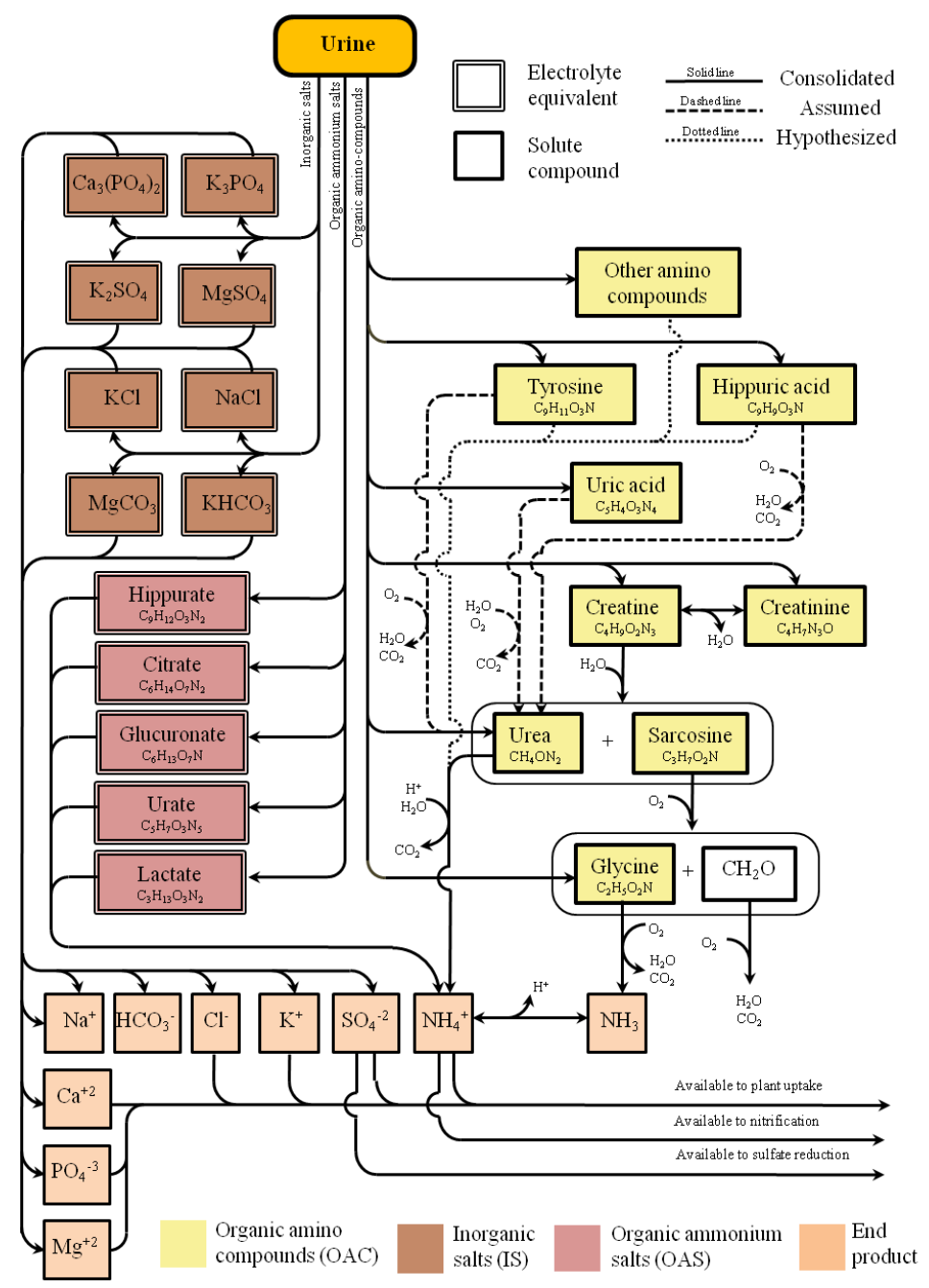

Figure 1. Chemical and biochemical breakdown pathways of major compounds found in human urine. Drawing is developed after Maggi and Daly (2013). 


\section{METHODS}

\subsection{Urine decomposition in soils}

Human urine is a mixture of more than 200 organic and inorganic compounds that include nitrogen, phosphorous and sulphur elements in various vitamins, hormones, organic acids, and salts. About 70 of these compounds have concentration higher than $10 \mathrm{mg} / \mathrm{L}$, and correspond to a mass of about $36.8 \mathrm{~g} / \mathrm{L}$; the remaining components only represent approximately $0.25 \mathrm{~g} / \mathrm{L}$ (Putnam, 1971).

The most abundant compounds are sorted in order of decreasing concentration in Table 1, and are grouped as organic amino compounds (OAC), organic ammonium salts (OAS) and inorganic salts (IS). OAC were selected from the effective ensemble of compounds detected in human urine, OAS were referenced as equivalent to a proposed concentration of solute ammonia $\mathrm{NH}_{3}{ }^{+}$, and IS were referenced to be equivalent to a proposed concentration of $\mathrm{Mg}^{+2}$, $\mathrm{PO}_{4}^{-3}, \mathrm{Ca}^{+2}, \mathrm{Na}^{+}, \mathrm{HCO}_{3}^{-}, \mathrm{Cl}^{-}, \mathrm{K}^{+}$, and $\mathrm{SO}_{4}{ }^{-2}$ ions. These OAC, OAS and IS were included in the reaction network of Figure 1, which has been extended to comprise all primary and secondary nutrients on the basis of the reaction network in Maggi and Daly (2013).

Of interest to our work here were the catabolic kinetic reactions that break OAC with higher stoichiometric $\mathrm{C}$ content down to compounds with sequentially lower $\mathrm{C}$ content. The reactions below refer to tyrosine oxydation, hypporic acid oxydation, uric acid oxydation, creatine hydrolysis, sarcosine oxydation, glycine oxydation and urea hydrolysis

$$
\begin{aligned}
& \underset{\text { Tyrosine }}{\mathrm{C}_{9} \mathrm{H}_{11} \mathrm{O}_{3} \mathrm{~N}+\frac{19}{2} \mathrm{O}_{2}} \rightarrow \frac{1}{2} \underset{\text { Urea }}{\mathrm{CH}_{4} \mathrm{ON}_{2}}+\frac{9}{2} \mathrm{H}_{2} \mathrm{O}+\frac{17}{2} \mathrm{CO}_{2}, \\
& \underset{\text { Hippuric acid }}{\mathrm{C}_{9} \mathrm{H}_{9} \mathrm{O}_{3} \mathrm{~N}+19 \mathrm{O}_{2}} \rightarrow \frac{1}{2} \underset{\text { Urea }}{\mathrm{CH}_{4} \mathrm{ON}_{2}}+\frac{7}{2} \mathrm{H}_{2} \mathrm{O}+\frac{17}{2} \mathrm{CO}_{2}, \\
& \underset{\text { Uric acid }}{\mathrm{C}_{5} \mathrm{H}_{4} \mathrm{O}_{3} \mathrm{~N}_{4}}+2 \mathrm{H}_{2} \mathrm{O}+\frac{3}{2} \mathrm{O}_{2} \rightarrow \underset{\text { Urea }}{2 \mathrm{CH}_{4} \mathrm{ON}_{2}}+3 \mathrm{CO}_{2}, \\
& \underset{\text { Creatine }}{\mathrm{C}_{5} \mathrm{H}_{9} \mathrm{O}_{2} \mathrm{~N}_{3}}+\mathrm{H}_{2} \mathrm{O} \rightarrow \underset{\text { Urea }}{\mathrm{CH}_{4} \mathrm{ON}_{2}}+\mathrm{C}_{3} \mathrm{H}_{7} \mathrm{O}_{2} \mathrm{~N},
\end{aligned}
$$




$$
\begin{aligned}
& \underset{\text { Sarcosine }}{\mathrm{C}_{3} \mathrm{H}_{7} \mathrm{O}_{2} \mathrm{~N}}+\frac{1}{2} \mathrm{O}_{2} \rightarrow \underset{\text { Glycine }}{\mathrm{C}_{2} \mathrm{H}_{5} \mathrm{O}_{2} \mathrm{~N}+\mathrm{CH}_{2} \mathrm{O},} \\
& \underset{\text { Glycine }}{\mathrm{C}_{2} \mathrm{H}_{5} \mathrm{O}_{2} \mathrm{~N}}+\frac{3}{2} \mathrm{O}_{2} \rightarrow \mathrm{NH}_{3}+\mathrm{H}_{2} \mathrm{O}+2 \mathrm{CO}_{2}, \\
& \underset{\text { Urea }}{\mathrm{CH}_{4} \mathrm{ON}_{2}}+2 \mathrm{H}^{+}+\mathrm{H}_{2} \mathrm{O} \rightarrow 2 \mathrm{NH}_{4}^{+}+\mathrm{CO}_{2} .
\end{aligned}
$$

Equilibrium complexation reactions were included for creatine and $\mathrm{NH}_{4}{ }^{+}$as

$$
\begin{aligned}
& \underset{\text { Creatine }}{\mathrm{C}_{5} \mathrm{H}_{9} \mathrm{O}_{2} \mathrm{~N}_{3}} \leftrightarrow \underset{\text { Creatinine }}{\mathrm{C}_{5} \mathrm{H}_{2} \mathrm{ON}_{3}}+\mathrm{H}_{2} \mathrm{O}, \\
& \mathrm{NH}_{4}^{+} \leftrightarrow \mathrm{NH}_{3}(a q)+\mathrm{H}^{+},
\end{aligned}
$$

while equilibrium protonation reactions of $\mathrm{PO}_{4}^{-3}, \mathrm{SO}_{4}{ }^{-2}, \mathrm{HCO}_{3}{ }^{-}$and $\mathrm{Cl}^{-}$, and complexation of $\mathrm{Na}^{+}, \mathrm{Cl}^{-}, \mathrm{K}^{+}$, $\mathrm{Ca}^{+2}$ and $\mathrm{Mg}^{+2}$ with other ions were not explicitly included here.

Volatilization of $\mathrm{NH} 3(a q)$ to $\mathrm{NH} 3(g)$ was accounted as a sink in the $\mathrm{N}$ mass balance, and was described by an equilibrium reaction as

$$
\mathrm{NH}_{3}(a q) \leftrightarrow \mathrm{NH}_{3}(g)
$$

The reation network in Figure 1 highlights that $\mathrm{NH}_{4}^{+}$and $\mathrm{SO}_{4}^{-2}$ provide an entry substrate compound to biological nitrification and sulphate reduction, respectively, but these processes were not accounted for in the model presented here.

\subsection{Modelling urine decomposition in soils}

Biological catabolic decomposition of OACs were described with Michaelis-Menten kinetics coupled with Monod microbial biomass dynamics (Bekins et al., 1998). Different microbial functional groups were used for the OACs. The full set of kinetic and equilibrium reactions were calibrated on various experimental data of individual compounds and are described in detail in Maggi and Daly (2013). The equilibrium reactions of creatine and creatinine as well as between $\mathrm{NH}_{3}(a q)$ and $\mathrm{NH}_{4}{ }^{+}$and between $\mathrm{NH}_{3}(a q)$ and $\mathrm{NH}_{3}(g)$ were

\begin{tabular}{|c|c|c|c|c|c|}
\hline Reaction & $\underset{\left[\mathrm{s}^{-1}\right] \times 10^{-6}}{\mu}$ & $\underset{\left[\mathrm{mol} \mathrm{L}^{-1}\right]}{\boldsymbol{K}}$ & $\begin{array}{c}\boldsymbol{Y} \\
{[\text { g C-bio }} \\
\text { g C_sub }^{-1} \text { ] }\end{array}$ & $\begin{array}{cl}\boldsymbol{Y} \\
{[\mathrm{mg} \mathrm{C} \text {-bio }} & \left.\text { mol C_sub }{ }^{-1}\right]\end{array}$ & $\underset{\left[\mathrm{s}^{-1}\right] \times 10^{-6}}{\boldsymbol{\delta}}$ \\
\hline Tyr $\rightarrow$ Urea & 1.51 & 1.28 & $2.72 \times 10^{-4}$ & $2.93 \times 10^{2}$ & 1.00 \\
\hline $\mathrm{HA} \rightarrow$ Urea & 1.51 & 1.28 & $2.72 \times 10^{-4}$ & $2.93 \times 10^{2}$ & 1.00 \\
\hline UA $\rightarrow$ Urea & 8.72 & $3.31 \times 10^{-1}$ & $9.39 \times 10^{-4}$ & $5.63 \times 10^{2}$ & 1.00 \\
\hline $\mathrm{Cr} \rightarrow \mathrm{Src}+$ Urea & 2.84 & $4.58 \times 10^{-4}$ & $4.82 \times 10^{-2}$ & $2.32 \times 10^{4}$ & 1.00 \\
\hline $\mathrm{Src} \rightarrow$ Gly & 4.04 & $1.90 \times 10^{-3}$ & $4.26 \times 10^{-1}$ & $1.53 \times 10^{5}$ & 1.00 \\
\hline Gly $\rightarrow$ NH3 & 2.85 & $7.29 \times 10^{-3}$ & $3.73 \times 10^{-1}$ & $8.95 \times 10^{4}$ & 1.00 \\
\hline Urea $\rightarrow \mathrm{NH}_{4}^{+}$ & 8.88 & $1.52 \times 10^{-3}$ & $2.77 \times 10^{-1}$ & $3.33 \times 10^{4}$ & 1.00 \\
\hline
\end{tabular}
determined by equilibrium constants.

Table 2. Summary of parameters relative to biological decomposition reactions of tyrosine (Tyr), hippuric acid (HA), uric acid (UA), creatine (Cr), sarcosine (Src), glycine (Gly), and urea (Urea), respectively, form Maggi and Daly (2013). Parameters are: maximum specifig growth rate, $\mu$; halfsaturation concentration $K$; biomass yield coefficient $Y$; and biomass mortalityrate $\delta$.

The reactions in Eq. (1)-(10) were implemented in a soil bucket model. A constant soil water volume, $V_{w}=1$ $\mathrm{L}$, was assumed at field capacity $(\psi=-33$ bar), i.e., any liquid amendment would result in leaching. For a given textural composition ( $30 \%$ sand, $35 \%$ silt and $35 \%$ clay), soil porosity $\phi=45.1 \%$, air-entry suction $\psi$ s $=-30.7 \mathrm{~cm}$, and pore volume distribution index $b=8.4$ were estimated according to Clapp and Hornberger (1978), and the water content, $\theta=0.34 \mathrm{~m}^{3} \mathrm{~m}^{-3}$, was determined; this corresponded to the saturation $\mathrm{S}=\theta / \phi=$ 0.75 . The soil control volume in the bucket model was therefore $V=V_{w} / \theta=2.9 \mathrm{~L}$. The inflow rate of urine compounds was arbitrarily controlled by the volumetric urine flow rate, $F$, and urine dilution factor, $D$ (for more details see Maggi and Daly, 2013).

The parameters determining the kinetic reactions of OACs in Section 2.1 were estimated by inverse problem solving against various experimental data sets (Maggi and Daly, 2013) and are reported in Table 2. The 
equilibrium constant relative the equilibrium reactions were known from the EQ3/6 thermodynamic database (Wolery, 1992).

\subsection{Nutrient demand rate by corn, potato, and soybean}

Data relative to nutrient demand for corn (Heard, 2004a), potato (Heard, 2004b), and soybean (Heard, 2006) were used with the reactive model. These data were valuable in that they included primary nutrients $(\mathrm{N}, \mathrm{P}$, and $\mathrm{K})$, secondary nutrients $(\mathrm{S}$, $\mathrm{Ca}$, and $\mathrm{Mg}$ ) and micronutrients $(\mathrm{Zn}, \mathrm{Fe}, \mathrm{Mn}, \mathrm{Cu}$ and B) although, for this work, only primary and secondary nutrients were used. Nutrient demand was estimated indirectly from the elemental biomass composition at different stages of plan growth. These data allowed us to determine the average daily nutrient demand in terms of uptake rate per square meter for the three crops under investigation here (see Table 3). The uptake rates were used as sinks in the kinetic

Table 3. Summary of nutrient demand for corn, potato and soybean crops elaborated from Heard (2004a, 2004b, 2006). ${ }^{(a)}$ measured over 100 days; ${ }^{(b)}$ measured over 87 days; ${ }^{(c)}$ measured over 84 days.

\begin{tabular}{cccc}
\hline Nutrient demand & $\begin{array}{c}\text { Corn }^{(\mathrm{a})} \\
{\left[\mathrm{mg} \mathrm{m}^{-2} \mathrm{~d}^{-1}\right]}\end{array}$ & $\begin{array}{c}\text { Potato }^{(\mathrm{b})} \\
{\left[\mathrm{mg} \mathrm{m}^{-2} \mathrm{~d}^{-1}\right]}\end{array}$ & $\begin{array}{c}\text { Soybean }^{(\mathrm{c})} \\
{\left[\mathrm{mg} \mathrm{m}^{-2} \mathrm{~d}^{-1}\right]}\end{array}$ \\
\hline $\mathrm{NH}_{4}^{+}-\mathrm{N}$ & 140.11 & 228.04 & 5.54 \\
$\mathrm{PO}_{4}^{-3}-\mathrm{P}$ & 80.70 & 88.89 & 1.80 \\
$\mathrm{~K}^{+}-\mathrm{K}$ & 144.59 & 425.16 & 5.66 \\
$\mathrm{SO}_{4}^{-2}-\mathrm{S}$ & 12.32 & 29.63 & 0.33 \\
$\mathrm{Ca}^{+2}-\mathrm{Ca}$ & 12.32 & 14.17 & 2.57 \\
$\mathrm{Mg}$ & 28.02 & 60.55 & 0.86 \\
\hline
\end{tabular}
and equilibrium equations describing the reaction network in Figure 1.

Simulations were carried out to investigate the extent to which human urine applications at various rates could match the nutrient uptake rate of corn, potato and soybean crops. The explored time frame for these simulations lasted for 120 days to cover the entire growing season of these crops. During this period of time, three urine frtilizations were practiced at rates equal to $0.01,0.05$, and $0.1 \mathrm{~L} \mathrm{~m}^{-2}$ at dilution $D=0.1$ (1 part of urine and 9 parts of water) at times equal to 0,35 , and 80 days from seedling, which corresponded to time $t=$ $0 \mathrm{~d}$ in our simulations. These applications were described in the reactive model as instantaneous sources of OACs, OASs, and ISs. It was assumed that the soil nutrient concentration at time $t=0 \mathrm{~d}$ was zero in order to emphasise how much and at which rate urine was required to meet the crop nutrient demand.

\section{RESULTS}

\subsection{Matching crop nutrient demand}

Results in Figure 2 report the percent of seasonal demand met by urine amendments. Panels in Figure 2a,b and $\mathrm{c}$ relative to an amendment of $0.01 \mathrm{~L} \mathrm{~m}^{-2}$ show that $100 \%$ of the demand was reached only for soybean,
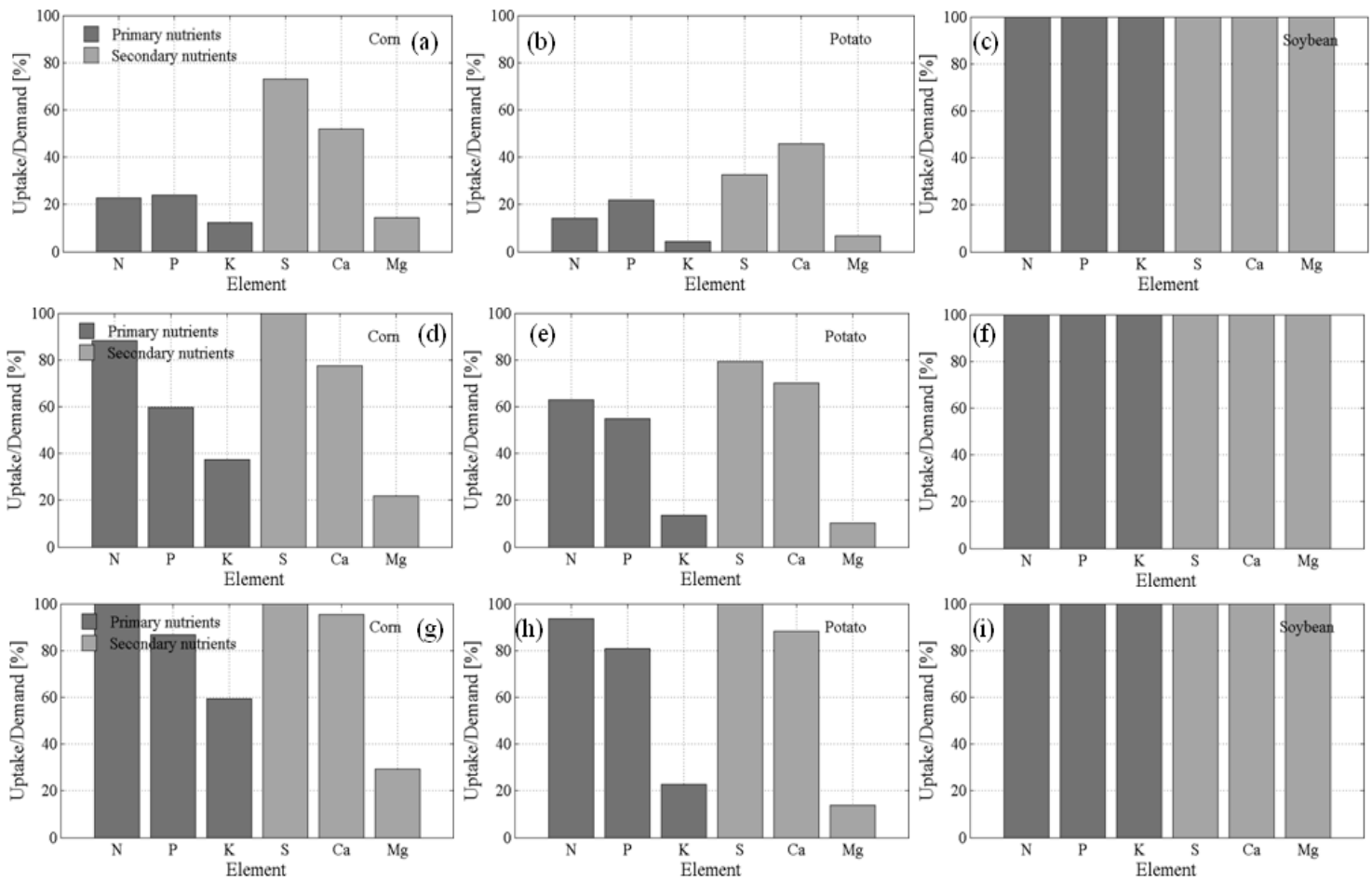

Figure 2. Ratio of elemental uptake over demand for corn, potato and soybean plants after three instantaneous human urine amendments of $0.01 \mathrm{Lm}^{-2}$ (panels a, b and c), $0.05 \mathrm{Lm}^{-2}$ (panels d, e, and f) and $0.1 \mathrm{Lm}^{-2}$ (panels $\mathrm{g}, \mathrm{h}$, and i) at dilution $D=0.1$ (1 part of urine and 9 parts of water). 
while corn and potato plants received less than $25 \%$ of required primary nutrients and less than $70 \%$ of secondary nutrients. Becasue soybean requires substantially less nutrient than corn and potato plants, any increase in urine amendments will exceed the nutrient demand and is not commented further here.

The panels in Figure 2d,e and f relative to an amendment of $0.05 \mathrm{~L} \mathrm{~m}^{-2}$ increased largely the nutrient supply to corn and potato plants, which satisified at least $10 \%$ and up to $85 \%$ of required primary nutrients, and from about $8 \%$ to $100 \%$ of required secondary nutrients.

Finally, the panels in Figure $2 \mathrm{~g}$, $\mathrm{h}$ and i, relative to an amendment of $0.1 \mathrm{~L} \mathrm{~m}^{-2}$, increased further the nutrient uptake by plants. Primary nutrients demand was satisfied by at least $50 \%$ in corn and $20 \%$ in potato, while secondary nutrients were supplied by at least $20 \%$ and $10 \%$ of the required amount, respectively. Note that, on average, at least $50 \%$ of primary and secondary nutrients together became available to plants. We infer that further increases in urine amendments would result in a better matching of the overall seasonal nutrient demand.

In running these simulations, we noted that an increase of urine amendment by a factor of 5 , from $0.01 \mathrm{~L} \mathrm{~m}^{-2}$ to $0.05 \mathrm{~L} \mathrm{~m}^{-2}$, did not result in a linear proportionality toward satisfaction of nutrient demand. A similar result was observed for amendments increased by a factor of 2 , from $0.05 \mathrm{~L} \mathrm{~m}^{-2}$ to $0.1 \mathrm{~L} \mathrm{~m}^{-2}$. These results were explained by nonlinearities in the biogeochemical concatenation of reactions and by losses of mobile ions as aqueous leachate and by $\mathrm{NH}_{3}(g)$.

\subsection{Analysis of chemicals dynamics}

With the capability to track each individual compound and microbial functional group in the reactive model, an analysis of the chemical dynamics over time can be carried out. While the OACs dynamics were analysed in detail in Maggi and Daly (2013), we focus here on the dynamics of the end-products of urine breakdown that are taken up by plants. Here, emphasis is therefore put on primary $\left(\mathrm{NH}_{4}{ }^{+}, \mathrm{PO}_{4}^{-3}\right.$, and $\left.\mathrm{K}^{+}\right)$and secondary $\left(\mathrm{SO}_{4}{ }^{-2}, \mathrm{Ca}^{+2}\right.$ and $\left.\mathrm{Mg}^{+2}\right)$ nutrients.

For this analysis we focused only on the case of urine application of $0.1 \mathrm{~L} \mathrm{~m}-2$ at dilution $D=0.1$ at time 0 , 35 and 80 days from seedling of corn plants. Sources of nutrient other than from urine amendments were excluded to better highlight the potential to supply primary and secondary nutirents from urine recycling. Sinks were included as leaching of all solute compounds (including molecules and ions) and as $\mathrm{NH}_{3}(g)$ volatilization. The results in Figure 3 report the available nutrient content, cumulative nutrient demand and cumulative uptake for each nutrient. In all panels in Figure 3, it is possible to note that the available nutrient content increased sharply in correspondence with urine applications. Nonlinearities were visible only for $\mathrm{NH}_{4}{ }^{+} \mathrm{N}$ due to the biological breakdown of OACs, while all other nutrients appeared as instantaneous peaks because no or equilibrium reactions were assumed that decomposed those compounds. It is noted that when the content of a nutrient approached zero, uptake of that nutrient became negligible, putting the crop under stress.

It is important to note that these result were obtained by arbitrarily chosing the timing and rate of each application. It is clear, though, that it is possible to mathematically formulate an objective function (for
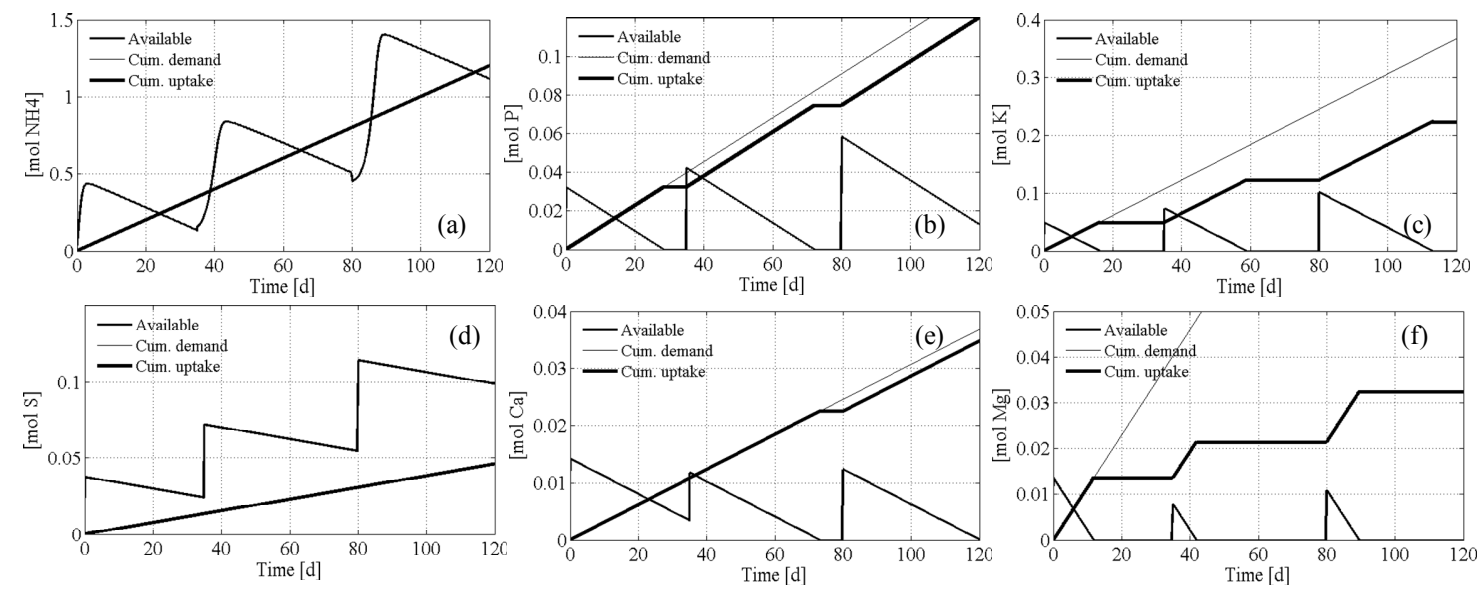

Figure 3. Dynamics of primary (panel a, b and c) and secondary (panels d, e and f) nutrients over 120 days in corn. Urine was applied at time 0,35 and 80 days from seedling as an instantaneous application of $0.1 \mathrm{~L} \mathrm{~m}^{-2}$ at dilution $D=0.1$ ( 1 par of urine and 9 parts of water). Curves represent the nutrient available content, cumulative plant demand, and cumulative uptake. 
example meeting the demand for each nutrient) and optimize timing, amendment rate and dilution against that function. This possible way to exploit the model is not presented here, but it is subject of current investigation.

\section{ACKNOWLEDGMENTS}

The authors thank Nathan Guerry for his contribution to the initial development of this project, who was supported by the Summer Scholarship Programme of the School of Civil Engineering, The University of Sydney.

\section{REFERENCES}

Adamsson M., (2000). Potential use of human urine by greenhouse culturing of microalgae (scenedesmus acuminatus), zooplankton (daphnia magna) and tomatoes (lycopersicon). Ecological Engineering, 16(2):243-254.

Akpan-Idiok A. U., Udo I. A., and Braide E. I., (2012). The use of human urine as an organic fertilizer in the production of okra (abelmoschus esculentus) in south eastern nigeria. Resources Conservation and Recycling, 62:14-20.

Bekins, B. A.; Warren, E.; Godsy, E. M. Ground, (1998), A comparison of zero-order, first-order and Monod biotransformation models, Water 36(2), 261-268.

Clapp, R.B.; Hornberger, G.M., (1978). Empirical equations for some soil hydraulic properties, Water Resour. Res., 14, 601-604.

Guzha E., Nhapi I., and Rockstrom J., (2005). An assessment of the effect of human faeces and urine on maize production and water productivity. Physics and Chemistry of the Earth, 30(11-16):840-845.

Heard J., (2004a), Nutrient Uptake and partitioning by grain corn in Manitoba, Manitoba Agronomists Conference 2004, December 14-15, University of Manitoba, Winnipeg, Manitoba.

Heard J., (2004b), Nutrient Uptake and partitioning by potatoes in Manitoba, Manitoba Agronomists Conference 2004, December 14-15, University of Manitoba, Winnipeg, Manitoba

Heard J., (2006), Nutrient Uptake and partitioning by soybeans in Manitoba, 7th Manitoba Agronomists Conference 2006, December 12-13, University of Manitoba, Winnipeg, Manitoba

Mnkeni P. N. S., Kutu F. R., Muchaonyerwa P., and Austin L. M., (2008). Evaluation of human urine as a source of nutrients for selected vegetables and maize under tunnel house conditions in the eastern cape, south africa. Waste Management \& Research, 26(2):132-139.

Maggi F., and Daly E., (2013). Decomposition pathways and rates of human urine in soils, Journal of Agricultural and Food Chemistry 61, 6175-6186.

Pradhan S. K., Nerg A. M., Sjoblom A., Holopainen J. K., and Heinonen-Tanski H., (2007). Use of human urine fertilizer in cultivation of cabbage (brassica oleracea)- impacts on chemical, microbial, and flavor quality. Journal of Agricultural and Food Chemistry, 55(21):8657-8663.

Pradhan S. K., Holopainen J. K., Weisell J., and Heinonen-Tanski H., (2010a). Human urine and wood ash as plant nutrients for red beet (beta vulgaris) cultivation: Impacts on yield quality. Journal of Agricultural and Food Chemistry, 58(3):2034-2039.

Pradhan S. K., Pitkanen S., and Heinonen-Tanski H., (2010b). Fertilizer value of urine in pumpkin (cucurbita maxima 1.) cultivation. Agricultural and Food Science, 19(1):57-67.

Putnam D., (1971). Composition and Concentrative Properties of Human Urine; NASA: Huntington Beach, CA, 1971; Vol. NASA CR-1802.

Wolery, T., (1992). EQ3/6, A Software Package for Geochemical Modeling of Aqueous Systems: Package Overview and Installation Guide (Version 7.0), Lawrence Livermore National Laboratory, University of California, Livermore, CA. 